\title{
How Dangerous Can Be Nasal Excessive Blowing
}

\author{
Cristina Otilia Laza*, Dan Mihail and Laura Axinte \\ ENT/OMF Clinic, Europe
}

Submission: July 29, 2017; Published: August 04, 2017

*Corresponding author: Cristina Otilia Laza, ENT/OMF Clinic, SF Apostol Andrei, Constanta, Romania, Europe, Email: cristinaotilia@gmail.com

\begin{abstract}
The patient presented here it's a very rare case of pneumosinus dilatans frontalis discovered accidentally and suddenly because of a spontaneous palpebral and orbital emphysema after a simple act of blowing his nose.

Pneumosinus dilatans is a rare pathology usually involving the frontal sinus, but is possible a ethmoidal, sphenoidal or a maxillary involvement. Definition of this entity - a progressive enlargement usually bilateral but sometimes unilateral with normal lining mucosa, no signs of infection and the sinus content just air. The cause of these disease is not known, there are a few theories like an obstruction of the naso-frontal duct with increased intrasinus pressure. The symptoms are poor /or absent -most of the cases frontal bossing is the first sign or it is a radiological discovery. But not all the large frontal sinuses are pneumosins dilatans-we have to prove progressive expansion, comparing on an annual X-ray the sizes of the sinus.
\end{abstract}

Keywords: Hipersinus; Pneumosinus dilatans; Pneumocele; Sinus hypertrophy; Hyperpneumatization

\section{Introduction}

Pneumatisation of the paranasal sinuses is highly variable, in some very rare cases tends to extends beyond the boundaries of the sinus in the bone causing progressive swelling of the sinus - pneumosinus dilatans. The lining epithelium is normal in these patients, the sinus content is just air, there are no signs of acute or chronic infection, the naso-frontal duct is free. The frontal sinus is involved unilateral possible bilateral but sphenoidal and maxillary sinuses are sometimes involves.

Abnormal expansion of the frontal sinus have also been given the names of sinus hypertrophy, sinus ectoma, aerocele, pneumatocele, pneumosinus dilatans probable all terms describe the same disease. About $20 \%$ of pneumosinus dilatans are associated with arachnoid cyst, meningioma, fibrous dysplasia, acromegaly, gigantism, Pneumosinus dilatans is very rare. The first description was attributed to Meyer in 1898 but the term pneumosinus dilatans was introduced by Benjamin in 1918. The largest study was reported by Bourdial, who published a series of 41 cases but without radiological documentation. More recently Urken and Legent reported new cases of pneumosinus dilatans, giving special attention to definition, possible etiologies of this rare process of expansion [1-2].

According to Urken there are three categories of enlarged frontal sinus:

a) hyper sinus (large sinus) b) pneumosinus dilatans (the entire sinus is abnormally expanded beyond the normal boundaries of the frontal bone)

c) pneumocele (aerated sinus with focal or generalized thinning of the bonny walls). Others authors consider all terms describing the same pathology.

\section{Pathogenesis}

The cause of the disease is not known, there are a few theories:

The obstruction of the naso-frontal duct create a valvular mechanism (ball valve- like) due to a large anterior ethmoidal cell and swelling of the mucosa (Harrison and Young-1955). This result in an progressive increase in intrasinusal pressure with enlargement of the sinus. But the studies about intrasinusal pressure with a cannula inserted in the naso-frontal duct connected to a manometer.

a) Abnormalities of the growth and sex hormones with hyperactivity.

b) A spontaneously discharge of a frontal mucocele.

Most studies and surgery shows a normal mucosa, a sterile cavity a normal cilliary activity and no abnormal bone activity [3]. 
Symptoms and Signs

The most frequent symptoms are:

a) Deformity

b) Frontal progressive bossing

c) Headache-frontal
The Most Important For The Diagnosis Is Imagistics X-ray a plain- in.

\section{Occipital-mental view (Water's view)}

(Figures $1 \mathrm{~A}$ and $1 \mathrm{~B})$.

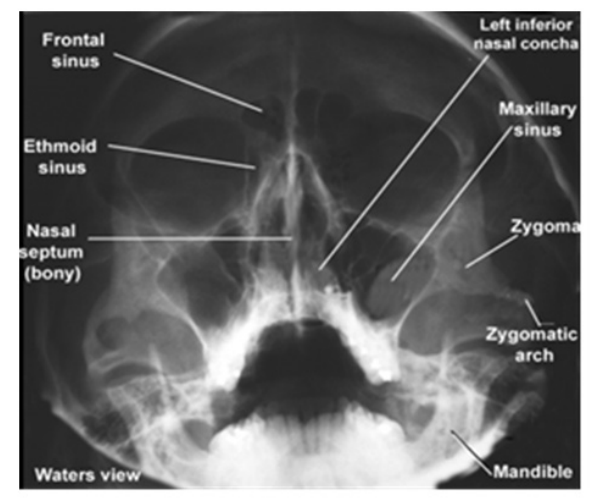

(1a)

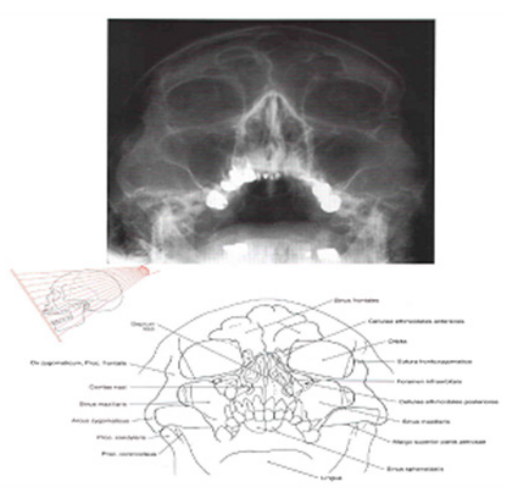

(1b)

Figure 1: Standard Waters view.

$1=$ Superior orbital rim; $2=$ frontal sinus; $3=$ zygomaticofrontal suture line; $4=$ medial wall of the orbit; $5=$ ethmoid sinus; $6=$ zygomatic body; $7=$ inferior orbital rim; $8=$ floor of the orbit; $9=$ medial and lateral walls of the maxillary sinus; and $10=$ nasal septum.

Occipital-frontal view (Caldwel view) - position is suited for frontal sinuses,because in this position the frontal sinuses are in direct contact with the film so no chance for any distortion or geometric blur to occur. Patient is sitting in front of the film with the radiographic base line tilted to an angle of 15 - 20 degrees upwards. The incident beam is horizontal and is centered $1 / 2$ inch below the external occipital protuberance (Figure 2).

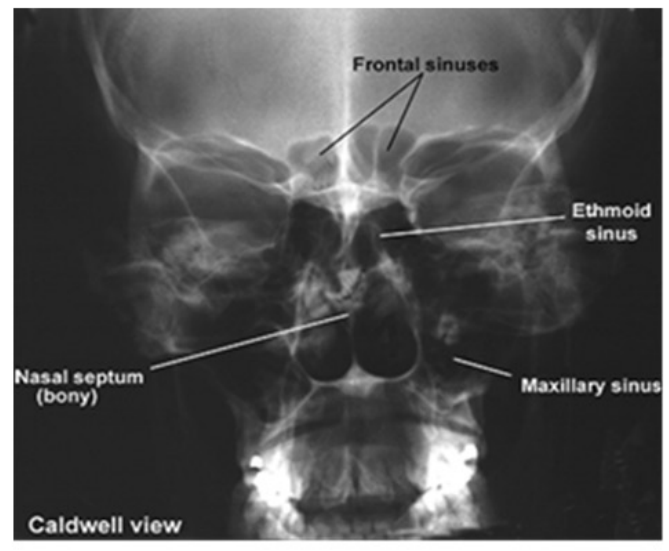

(2a)

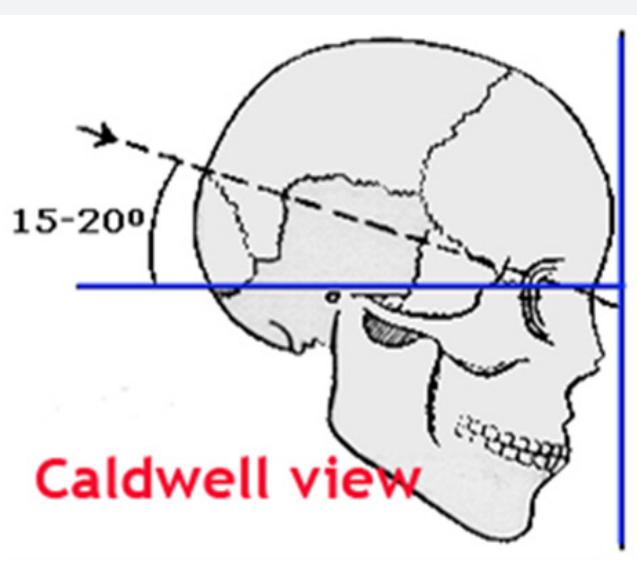

(2b)

Figure 2: Occipital-frontal view (Caldwel view) - position is suited for frontal sinuses, because in this position the frontal sinuses are in direct contact with the film so no chance for any distortion or geometric blur to occur. Patient is sitting in front of the film with the radiographic base line tilted to an angle of $15-20$ degrees upwards. The incident beam is horizontal and is centered 1/2 inch below the external occipital protuberance.

Submento-vertical position (Hirtz position): demonstrate fluids in sphenoid sinuses,also thicknesses of the bony walls of the antrum and the frontal sinuses.Patient is arched as far as possible so that the base of skull is parallel to the film,and $x$ ray beam is centered in the midline at a point between the angles of the jaws,or in the supine position with the head hanging back over the end of the tab (Figure 3). 


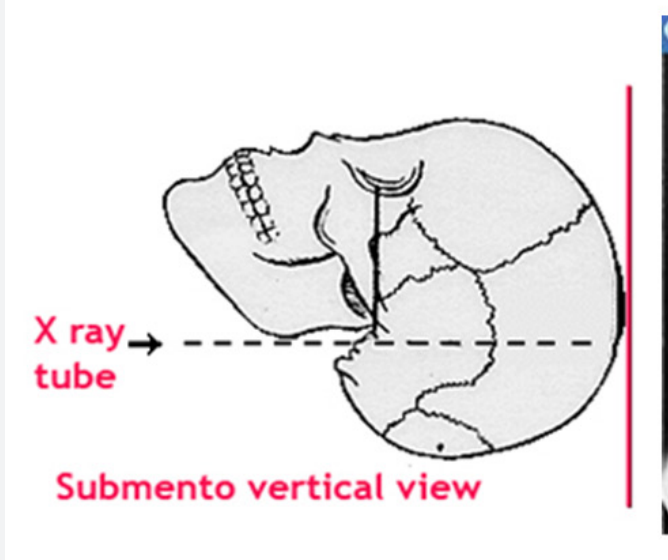

(3a)

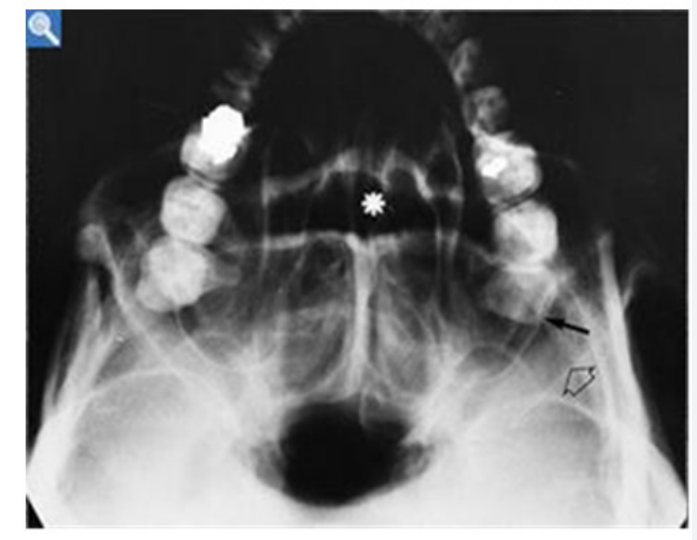

(3b)

Figure 3: Submento-vertical position (Hirtz position): demonstrate fluids in sphenoid sinuses,also thicknesses of the bony walls of the antrum and the frontal sinuses. Patient is arched as far as possible so that the base of skull is parallel to the film, and $\mathrm{x}$ ray beam is centered in the midline at a point between the angles of the jaws, or in the supine position with the head hanging back over the end of the tab

Lateral view: helps in distinguishing the various pathologies of the frontal sinuses, if loss of translucency is due to thickening of the anterior bony wall or infection of the frontal sinus per se, also demonstrates fluid levels in the antrum, gives information on the nasopharynx and soft palat, like enlargement of adenoid tissue (Figure 4).

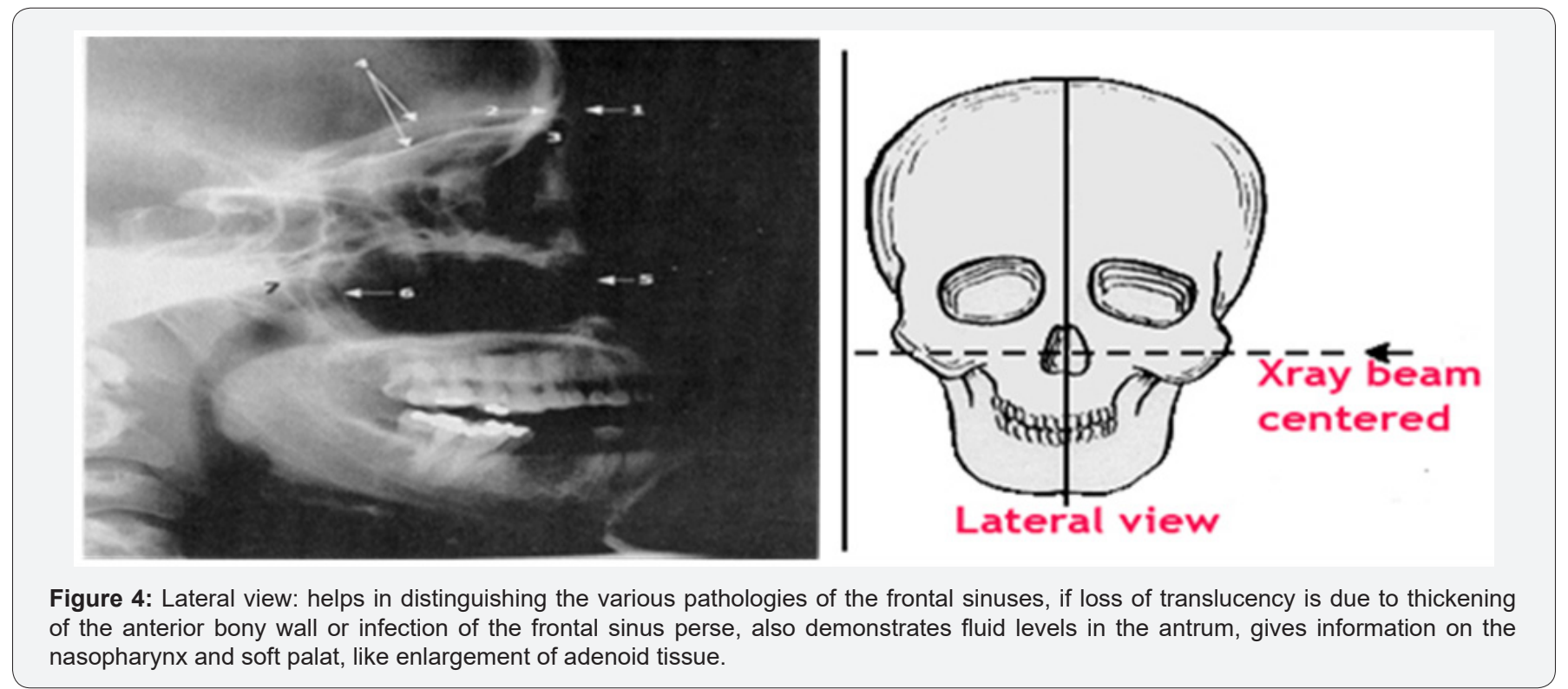

Oblique view 39 Degrees oblique (Rhese position)is demonstrating posterior ethmoid air cells and optic foramen, patient is made to sit facing the film, the head is rotated so that the sagittal plane is moved to an angle of 39 degrees. The radiographic base line is at an angle of 30 degrees to the horizontal.

\section{Computed Tomography (CT)}

a) Most informative radiographic exam for head and neck trauma [4]. b) Axial and coronal facial CT with bone and soft tissue windows, 2-3 mm sections; orbital cuts (coronal) if suspect orbital fractures, CT of head for intracranial injury, CT of neck for laryngeal trauma

c) Inspect Areas of Concern: skull base, orbit (walls, floor, retrobulbar hematoma, muscle entrapment), vertical buttresses, horizontal beams, zygomatic arch, bony palate, mandible (condyles), soft tissue (fluid in sinuses, subcutaneous air, hematomas, etc) [5] (Figure 5). 

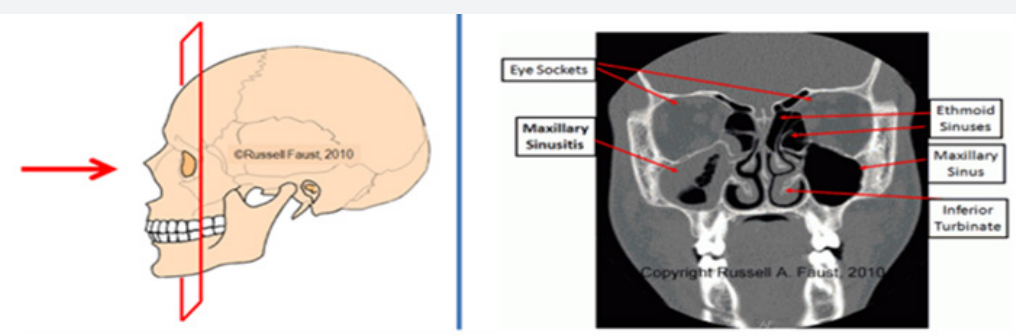

(5a) Coronal Plane
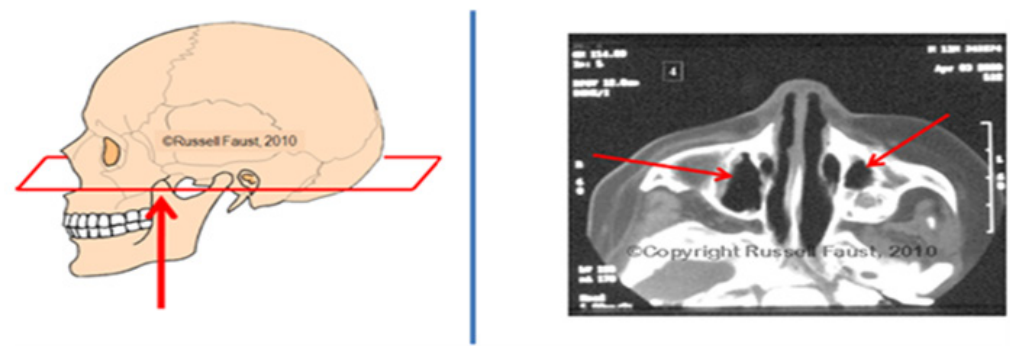

5(B) Axial|Plane.

Figure 5: Oblique view 39 Degrees oblique (Rhese position)- is demonstrating posterior ethmoid air cells and optic foramen, patient is made to sit facing the film, the head is rotated so that the sagittal plane is moved to an angle of 39 degrees. The radiographic base line is at an angle of 30 degrees to the horizontal.

\section{CAT scan}

Modalities of imaging are slowly losing their relevance. CT scan cranio-cerebral and face-we can have exactly the real size of the sinus measuring the highest vertical-of the sinus, and the horizontal size from the left to right, and in profile anteroposterior diameter, Also we can determine the fronto-nasal channel permeability, consequences around, complications or associated cerebraltumor to obtain two measurements in the vertical portion of the frontal sinus. Axial and coronal CT section are also important to determine the maximum depth of the sinus, the possible compression on the orbits, frontal lobe, the thinning of the sinus walls or an associated cerebral tumor like an meningioma. It is also important a hormonal profile concerning growth and sex hormones.

CT scan cranio-cerebral and face- we can have exactly the real size of the sinus measuring the highest vertical-of the sinus, and the horizontal size from the left to right, and in profile anteroposterior diameter, Also we can determine the fronto-nasal channel permeability, consequences around, complications or associated cerebraltumor to obtain two measurements in the vertical portion of the frontal sinus. Axial and coronal CT section are also important to determine the maximum depth of the sinus, the possible compression on the orbits, frontal lobe, the thinning of the sinus walls or an associated cerebral tumor like an meningioma. It is also important a hormonal profile concerning growth and sex hormones [6].

\section{Complications}

The most frequent complication is:

a) proptosis , exophtalmia with a inferolateral displacement of the globe,

b) recurrent ,orbital cellulitis/abscess, diplopia,
ophtalmoplegia

c) frontal sinusitis, pansinusitis, frequent frontal barotraumas,

d) aesthetic-deformities of the frontal antherior wallbossing, endocranial-pneumoencephalocele,

e) Nervous- trigeminal deficit, anosmia, amaurosiiss.

\section{Differential Diagnosis}

The most important differential diagnosis are:
a) Acromegaly
b) Exostosis
c) Frontal osteoma
d) Frontal mucocele.

\section{Treatment}

The treatment is usually dispensarisation annual plain film to appreciate the rate of expansion. Despite the confusion about the pathogenesis and classification on pneumosinus dilatans the therapeutic options are clear:

a) in high intrasinusal patients with asymptomatic pneumosinus dilatans the treatment of choice is functional endoscopic surgery FESS with enlargement of the frontonasal duct

b) when frontal bossing is important open surgery with osteoplastic flap, with aesthetic modelation of the antherior wall, or sinus exclusion with fat or bone and obliteration of the frontal canal to minimize recurrence [7] (Figure 6). 


\section{Global Journal of Otolaryngology}

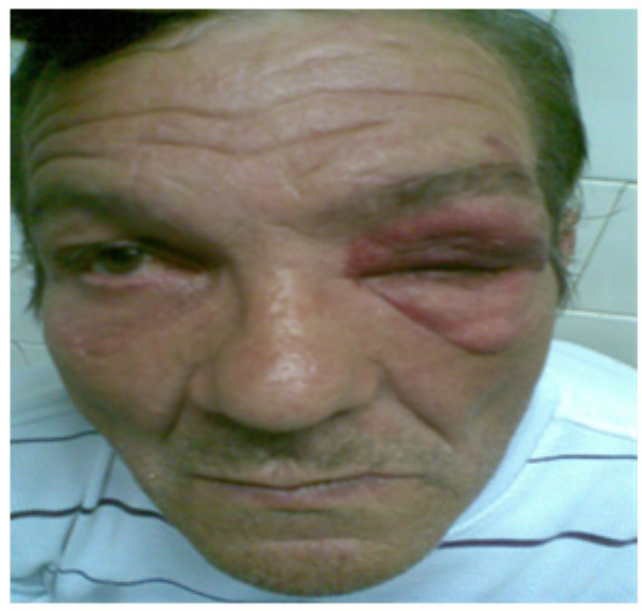

(6a)

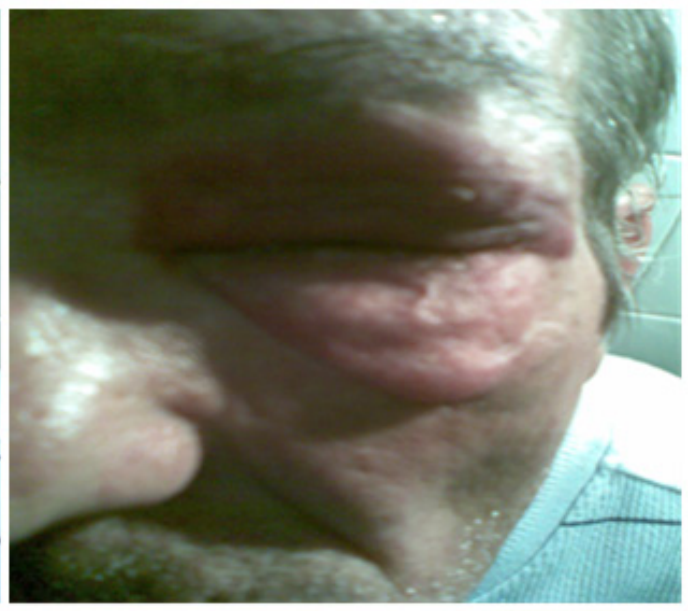

(6b)

Figure 6: Left Eye -Palpebral Emphysema, edema, bilateral marked frontal bossing.

\section{Case Report}

A 56 year old man presented to the emergency room of our institution for a sudden palpebral and orbital left emphysema after blowing his nose 2 days ago. He reported no history of recent trauma, prior sinus surgery, fever, chill, or photophobia and he had no clinically relevant medical history. Physical examination revealed a afebrile, alert, and oriented patient with a marked bilateral smooth bony swelling like a frontal bossing, palpebral edema, emphysema on the left side, orbital left emphysema, chemosis, no signs of visual imparity. Mobility of the eye ball was normal, even a little bit of exophthalmia was visible cause by intraorbital air, no diplopia, no complains of visual imparity. The sinuses point nonpainfull, crepitation in the superior and inferior left eyelids.

At the anterior rhinos copy the nasal cavities are quite normal with normal calibrum, normal pituitary mucosa and no abnormal discharge. Endoscopy of the nasal cavities-no causes of obstruction, no signs of trauma-epistaxis or infections. The $\mathrm{x}$-ray in Caldwell incidence and profile revealed a very large frontal sinus with thin walls but clear no abnormal opacities so that the diagnosis was a radiological discovery. The patients refuse a more complete examination on a spiral CT-scan and ophthalmology. Fortunately his wife bring us an older X-ray of the sinuses for an odontogenic sinusitis. Comparing the films at 27 years distance we observe an important development of the frontal sinus in an adult 48 years old.

The patient was advise to avoid blowing the nose for 4 weeks also we offered medical treatment with antibiotics, steroids in a short course to reduce edema, nasal decongestants and local corticosteroids to maintain fronto-nasal duct free, and drops with steroids and antibiotic for the eye and he was discharged after 24 hours of observation. At follow up 2 weeks later the patient was asymptomatic, he refuse annual imaging control ,because of irradiation ,but he swore he will came in time if a symptom will appear [8] (Figures 7 \& 8).

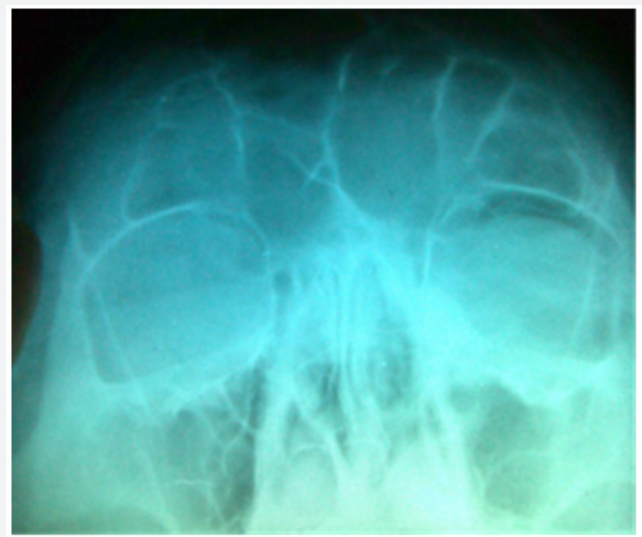

Figure 7: Radiology of the anterior sinuses- Caldwell view-bilateral hyperpneumatization of the frontal sinus. 


\section{Global Journal of Otolaryngology}

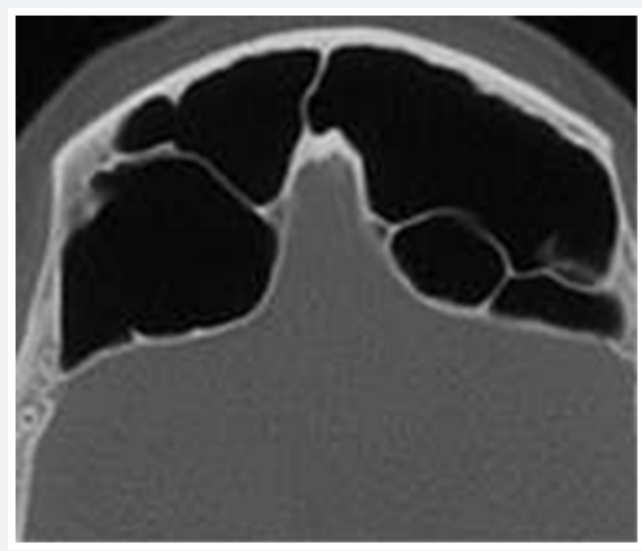

Figure 8: CT scans coronal view of the giant frontal sinuses.

\section{Conclusion}

I. Pneumosinus dilatans is a rare disease usually involving frontal sinus.

II. Most patients are asymptomatic and the diagnosis is a radiological discovery.

III. To prove expansion compare the RX sinuses recommended once per year but difficult to do -all asymptomatic patients refuse an inutile irradiation.

IV. In literature is also known as pneumocele, hyperpneumatization, hypersinus.

V. There are a few theories about the pathogenesis of the extension of the sinus but without serious arguments.

VI. Imaging is essential for the diagnosis but also for the evaluating of associated pathology like meningioma.

VII. The treatment is essential surgical using endoscopy or classic frontal surgery.

VIII. In traumas or surgery for tumors can cause lots of problems, from recurrent infection till end cranial, orbital complications [9].

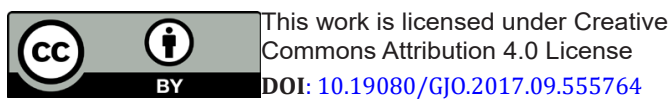

\section{References}

1. Benjamin LE (1919) Pneumosinus frontalis dilatans. Acta Otolaryngology (Stochlm) 1: 412-22.

2. Urken ML, Som PM, LawsonW (1987) The abnormally large frontal sinus. A practical method for it,s determination based upon analysis of 100 normal patients. Laryngoscope 97(5): 602-605.

3. Bourdial J Le (1970) pneumosinus dilatans des sinus frontal. Ann Otolaryngology Chr Cervicofaciala 87: 405-436.

4. Harrison MS, Young (1955) Pneumosinus frontalis. J Laryngol Otol 69: 108-114.

5. Smith IM, Maran AG, von Haacke NP (1987) Pneumosinus dilatans Ann Otol Rhinolaryng 96: 210-202.

6. Legent F, Bourdure P, Korb G (1991) Pneumosinus dilatans. Ann Otolaryng Chir Cervicofac 108: 30-34.

7. Jannert M (1994) Methods for measurements evaluation of the maxillary and frontal ostial function. Acta Otolaryngol Suppl 515: 1217.

8. Borrelli G. Tansell G (1979) Sphenoidal pneumosinus dilatans-a case report. Radiol Med 65: 735-739.

9. Benedikt RA, Brown DC (1991) Spontaneous drainage of an ethmoidal mucocel. A possible cause of pneumosinus dilatans. Ann J Neuroradiol 12: 729-31.

\section{Your next submission with Juniper Publishers will reach you the below assets}

- Quality Editorial service

- Swift Peer Review

- Reprints availability

- E-prints Service

- Manuscript Podcast for convenient understanding

- Global attainment for your research

- Manuscript accessibility in different formats

( Pdf, E-pub, Full Text, Audio)

- Unceasing customer service

Track the below URL for one-step submission https://juniperpublishers.com/online-submission.php 